Review

\title{
Comparison of Minimal Residual Disease Detection by Multiparameter Flow Cytometry, ASO-qPCR, Droplet Digital PCR, and Deep Sequencing in Patients with Multiple Myeloma Who Underwent Autologous Stem Cell Transplantation
}

\author{
Hiroyuki Takamatsu \\ Hematology/Respiratory Medicine, Faculty of Medicine, Institute of Medical, Pharmaceutical and Health Sciences, \\ Kanazawa University, 13-1 Takaramachi, Kanazawa, Ishikawa 920-8641, Japan; takamaz@staff.kanazawa-u.ac.jp; \\ Tel.: +81-76-265-2276; Fax: +81-76-234-4252
}

Academic Editor: Marco Ladetto

Received: 30 April 2017; Accepted: 20 September 2017; Published: 25 September 2017

\begin{abstract}
Multiple myeloma (MM) is a hematological malignancy with a poor prognosis, characterized by clonal proliferation of plasma cells in the bone marrow (BM). Relapse due to undetected minimal residual disease (MRD) is the leading cause of death among patients with MM. This review summarizes the methods and prognostic value of MRD assessment in BM and autografts from MM patients who underwent autologous stem cell transplantation (ASCT) by multiparameter flow cytometry (MFC), allele-specific oligonucleotide real-time quantitative PCR (ASO-qPCR), droplet digital PCR (ddPCR), and next-generation sequencing (NGS)-based detection methods. MRD assessment using NGS-based approaches has clear prognostic value and better sensitivity compared to traditional methods.
\end{abstract}

Keywords: multiple myeloma; minimal residual disease; allele-specific oligonucleotide-PCR; droplet digital PCR; next-generation sequencing

\section{Introduction}

The complete response (CR) rate in multiple myeloma (MM) cases remained below 10\% until the emergence of high-dose melphalan therapy with autologous stem cell transplantation (HDM-ASCT) [1,2] and novel agents such as proteasome inhibitors (PI) [3-5], immunomodulatory drugs (IMiDs) [6-8], and monoclonal antibodies [9-11]. These developments have increased CR rates up to $80 \%$ [12], and increasing numbers of MM patients have been able to achieve extremely deep CR wherein minimal residual disease (MRD) is not detected, even by highly sensitive methods. Hence, the International Myeloma Working Group (IMWG) recently proposed therapeutic effect assessment criteria based on MRD examination methods [13]. In this report, I review MRD detection methods that will potentially enable further stratification of $\mathrm{CR}$ cases in $\mathrm{MM}$, according to the literature.

\section{MRD Detection Methods}

\subsection{Multiparameter Flow Cytometry}

Multiparameter flow cytometry (MFC) (four or more colors) is frequently applied in clinical practice for the detection of MRD [14-22], and although its sensitivity (approximately $10^{-4}$ ) is inferior to that of the allele-specific oligonucleotide-PCR (ASO-PCR) assay, there is little difference between the clinical values of these methods [15]. Previous IMWG criteria define immunophenotypic CR 
(iCR) as stringent CR (sCR), in which MRD is not detected by MFC [23]. Rawstron et al. used six-color MFC (CD138/CD38/CD45/CD19/CD56/CD27, with CD81/CD117 when required) to analyze bone marrow (BM) MRD in patients who underwent HDM-ASCT $(n=397)$ and those who did not $(n=245)$. They found that MRD-negative patients at day 100 after HDM-ASCT exhibited longer median progression-free survival (PFS) $(28.6$ vs. 15.5 months; $p<0.001)$ and median overall survival (OS) (80.6 vs. 59.0 months; $p=0.0183$ ), whereas patients without HDM-ASCT who were MRD-negative after remission induction therapy only exhibited a longer PFS (10.5 vs. 7.4 months; $p=0.1)$ [14]. An analysis of the survival rates of these patients who underwent HDM-ASCT $(n=397)$ revealed that both PFS and OS were clearly stratified by MRD levels (across the 5-log MRD range $\left(<10^{-4}\right.$ to $\left.10^{-1} \leq\right)$, the median PFS values were $3.1,2.7,1.9,1.7$ and 0.8 years, respectively $(p<0.001)$; median OS values were "not reached", 6.8, 5.9, 4 and 1 , respectively $(p<0.001))$, and this stratification was also observed when the analysis was limited to patients who achieved CR [24].

According to earlier studies, the MFC technique can be applied in many patients and has advantages in terms of cost and rapidity [24-26], but it has not been standardized worldwide [27]. Furthermore, surface antigen patterns of myeloma cells may change from those at the time of initial diagnosis, raising the possibility of false negative results [28]. EuroFlow is therefore developing a test method called Next-Generation Flow MRD (NGF-MRD) with the aim of making it the global standard [29]. EuroFlow's MFC is an eight-color detection method using two tubes (tube 1: CD138/CD27/CD38/CD56/CD45/CD19/CD117/CD81; tube 2: CD138/CD27/CD38/CD56/CD45/ CD19/CyIgK/CyIgL) [29]. A comparative study of processing methods for hemolysis, device settings, and analysis software showed that NGF-MRD exhibited good reproducibility and detected MRD with a high sensitivity of $10^{-5}-10^{-6}$, and its results correlated well with those of next-generation sequencing (NGS) [29]. EuroFlow is also currently developing a method to apply NGF-MRD to identify and quantify myeloma cells using the EuroFlow database and automated software. This method would allow almost complete automation of flow cytometry gating analysis. Studies have already shown that automated software results correlate well with those of expert manual analysis [29]. Figure 1 illustrates an example of the application of NGF in our department. The NGF-MRD method is expected to become widely applied worldwide soon, but its clinical value remains to be demonstrated in future clinical studies.

\section{2. $A S O-P C R$}

In ASO-PCR, patient-specific primers are generated using the immunoglobulin complementaritydetermining region (CDR) III, which exhibits diversity in each patient, and PCR is performed using these primers to detect MRD (Figure 2, author's original figure) [30]. This method has an MRD detection sensitivity of $10^{-4}-10^{-6}$ [31-36]. Puig et al. compared the results of ASO-quantitative PCR (ASO-qPCR) with those of MFC for the detection of MRD [15] and found that MRD was successfully determined by ASO-qPCR in 71 of 170 patients $(42 \%)$ who achieved partial response (PR) or better. When MRD analysis was carried out in post-treatment BM in 103 patients, including 32 reported in previous studies, $54 \%$ and $46 \%$ were found to be MRD-positive by ASO-qPCR and MFC, respectively. Although a strong correlation was found between the MRD levels of ASO-qPCR and those of MFC $(r=0.881, p<0.001)$, ASO-qPCR showed a greater sensitivity. Analysis of 62 patients who achieved CR showed that patients with MRD $<10^{-4}$ had significantly better PFS (ASO-qPCR: median PFS 49 vs. 26 months, $p=0.001$; MFC: median PFS 45 vs. 25 months, $p=0.001$ ) and a significant difference in OS (ASO-qPCR: median PFS not reached vs. 60 months, $p=0.008$; MFC: median PFS 72 vs. 45 months, $p=0.014$ ). Oliva et al. presented the results of MRD evaluation by ASO-qPCR in the RV-MM-EMN-441 and RV-MM-COOP-0556 trials [37,38]. MRD assessment by ASO-qPCR was carried out after the intensification therapy or ASCT, as well as every six months until progressive disease or death during maintenance therapy. ASO-qPCR was performed according to the Euro-MRD guidelines [39]. The subjects were 105 patients who had achieved very good partial response (VGPR) or better after intensification/ASCT therapy, among whom patient-specific primers were generated 
for 73 patients $(70 \%)$. The patients who achieved molecular CR (mCR) after intensification/ASCT therapy comprised 19/35 (54\%) of those who underwent ASCT, but only 14/38 (37\%) of those who did not. Of the 40 patients who had not achieved mCR after intensification/ASCT therapy, 11 (27\%) achieved $\mathrm{mCR}$ during maintenance therapy. The impact of $\mathrm{mCR}$ on outcome after consolidation was as follows: median PFS was 48.8 months versus not reached in non-mCR vs. mCR patients $(p=0.01)$ (a median follow-up of 44 months). In multivariate analysis, the risk of progression/death was higher for International Staging System (ISS) stage (II/III vs. I) (hazard ratio (HR) 2.05), high-risk vs. standard-risk fluorescence in situ hybridization (FISH) (HR 2.31), age $>60$ vs. $\leq 60$ (HR 3.10), and non-mCR vs. mCR (HR 4.39). High-risk FISH patients with mCR had similar PFS as those with standard-risk FISH with $\mathrm{mCR}$, and better PFS than non-mCR standard-risk patients (updated results were available in the poster presented at ASH 2016).
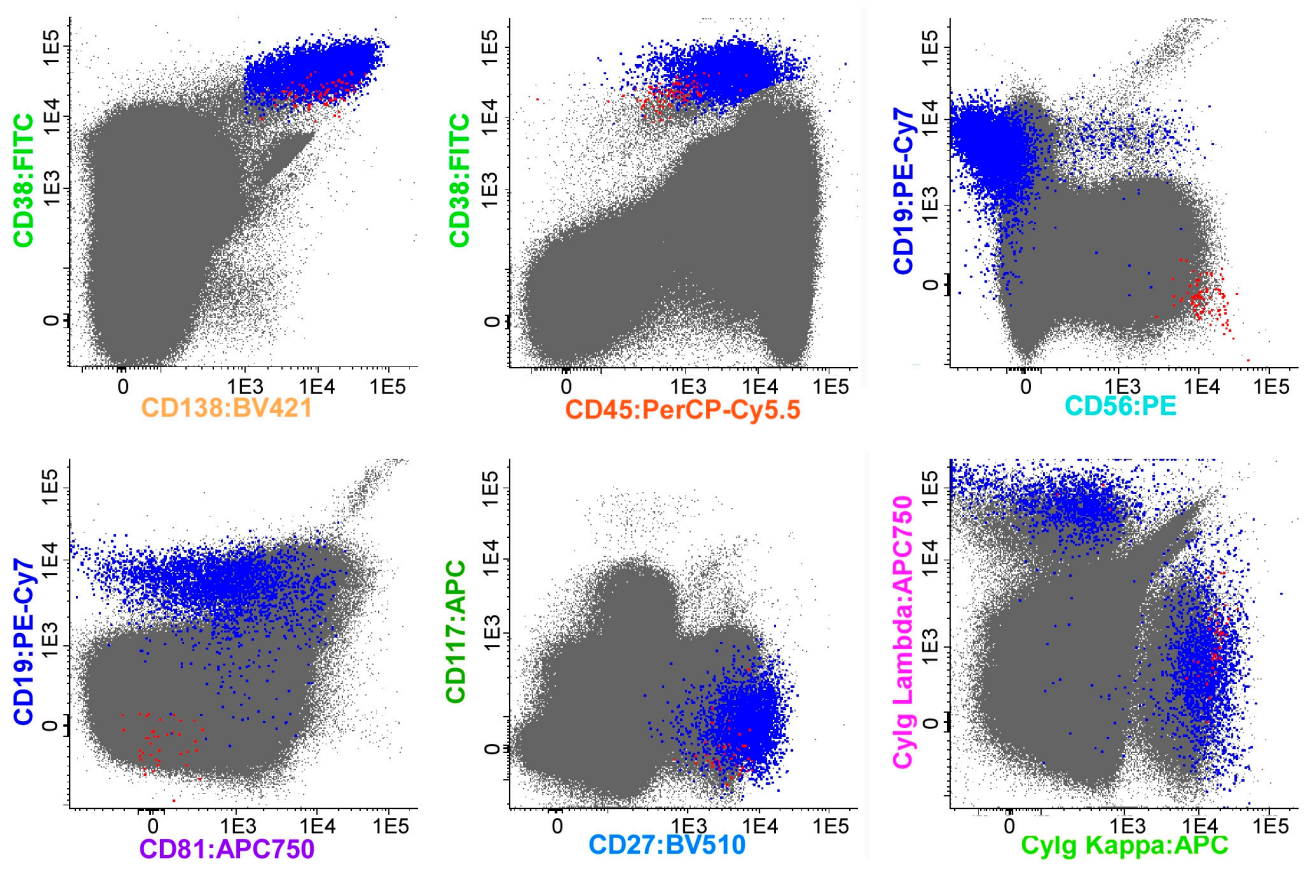

Figure 1. An example of the Next-Generation Flow (NGF) method based on the analysis of (merged) data files corresponding to a bone marrow (BM) sample from multiple myeloma (MM) ( $>10^{7}$ cells) with low levels of minimal residual disease (MRD), stained with the NGF-MM MRD panel. The figure shows bivariate dot plot representations in which plasma cells (PCs; blue and red dots) were gated using a conventional manual analysis strategy. Normal PCs (blue dots) display characteristic normal patterns of expression for the surface membrane markers used with a cytoplasmic (Cy) Igk vs. CyIg $\lambda$ ratio of 1.3. In contrast, clonal/aberrant PCs (red dots) can be clearly discriminated from normal PCs based on their more homogeneous phenotypic profile, the presence of myeloma-associated phenotypes (CD138hi, CD38dim, CD19-, CD81-, CD117-, and CD27dim), and a restricted pattern of expression of CyIgk. Other non-PC BM populations are depicted as gray dots. Please note that, in this sample, PCs corresponded to $0.06 \%$ of all nucleated BM cells; in turn, aberrant PCs corresponded to $0.0007 \%$ of the whole BM cellularity, with an assay sensitivity (in the quantitative range) of $<5 \times 10^{-6}$. 


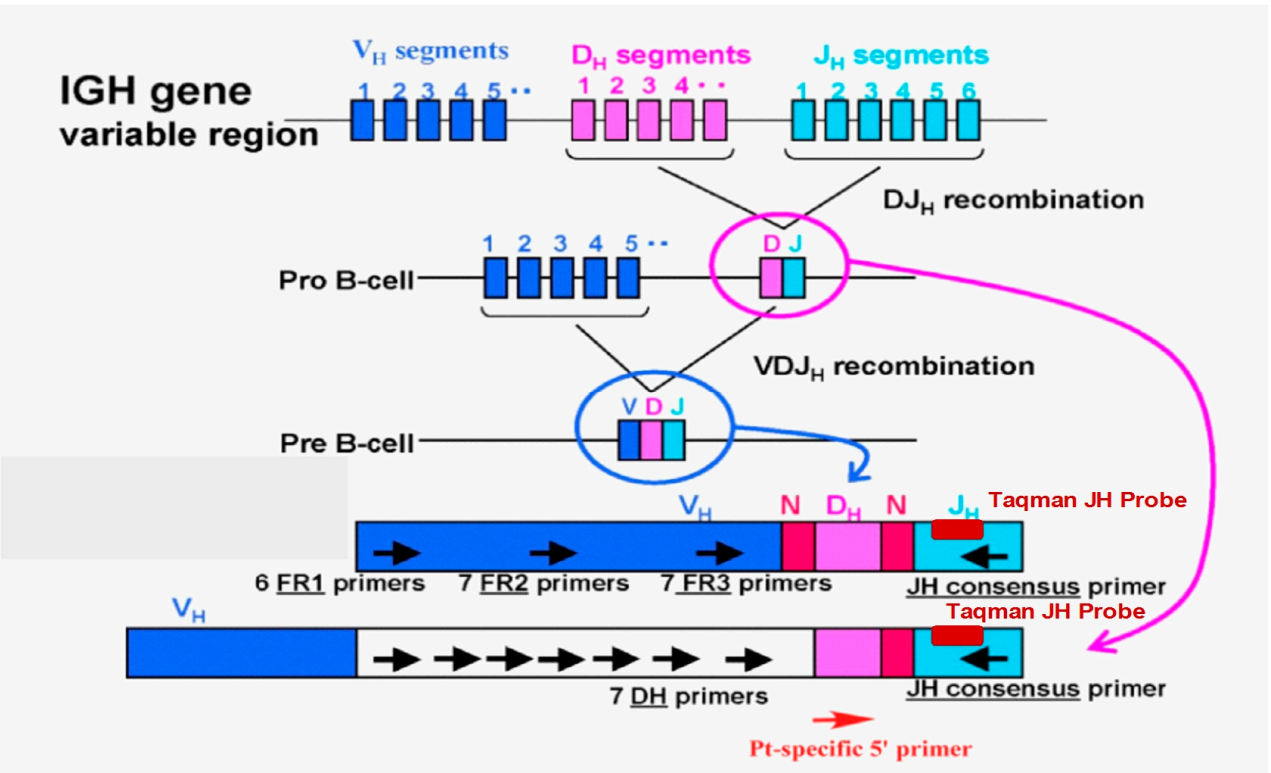

Figure 2. Allele-specific oligonucleotide-quantitative PCR (ASO-qPCR) method to detect minimal residual disease (MRD), and design of ASO-qPCR primers and probes.

\subsection{Droplet Digital PCR}

MRD is currently being detected by ASO-qPCR, which requires calibration curves that are generated from high-quality DNA samples collected at the time of diagnosis. Droplet digital PCR (ddPCR), which does not need calibration curves, has recently been adopted for MRD measurements to avoid this problem. Its principle is as follows: the sample is divided among a large number of reaction wells, and PCR is performed for the target gene; wells that contain the target gene count as positive by PCR amplification, and those that do not count as negative. Since ddPCR involves counting of positive wells (positive rate), it offers the advantage of enabling direct and absolute quantitation without requiring comparison with a reference or standard sample [40]. Drandi et al. reported that ddPCR of immunoglobulin gene rearrangement had sensitivity, accuracy, and reproducibility comparable with those of qPCR when using BM and peripheral blood of $18 \mathrm{MM}$ and 21 mantle cell lymphoma patients. However, thus far, there have been no data to predict outcomes using ddPCR in a controlled clinical setting or multi-laboratory standardization programs [41].

\subsection{NGS}

A new method of assessing MRD has recently been developed, which combines NGS and PCR. In practical terms, patient-specific regions (the $\mathrm{IgH}-\mathrm{VJ} / \mathrm{DJ}$ and $\mathrm{IgK}$ regions) of DNA extracted from samples are amplified by PCR; tag sequences are added to the PCR products; and the sequences are again amplified by PCR using primers for the J and tag sequences. The patient-specific sequences of these PCR products are sequenced at least $10^{6}$ times at high throughput by NGS, which can detect even tiny amounts of clonal sequences in the sample. Since this method does not require the generation of patient-specific PCR primers, it is capable of cheap and rapid MRD detection at the $10^{-6}$ level (Figure 3A; the original figure was modified for consistency with Figure 2) [42-47].

Attal et al. applied this NGS method to evaluate MRD in BM in the IFM/DFCI 2009 clinical trial, using combination therapy with new drugs (bortezomib-lenalidomide-dexamethasone (VRD)) [48]. Of $131 \mathrm{MM}$ patients who achieved CR after maintenance therapy with lenalidomide, 80 patients were MRD-negative $\left(<10^{-6}\right)$, and these patients achieved significantly better PFS than the 51 patients who were MRD-positive (three-year PFS 92\% vs. 64\%) [49]. At the 2016 Annual Meeting of the American Society of Hematology, MRD analysis results from clinical studies of two different 
combination therapies using daratumumab, an anti-CD38 monoclonal antibody, were reported: the POLLUX study of daratumumab-lenalidomide-dexamethasone (DRd) [10] and the CASTOR study of daratumumab-bortezomib-dexamethasone (DVd) [11] for relapsed/refractory MM [50]. Although the subjects were patients with relapsed/refractory MM, $12 \%$ of those who received DRd therapy and $4 \%$ of those who received DVd therapy achieved MRD negativity with a sensitivity of $10^{-6}$. For those who received either DRd or DVd therapy and achieved MRD negativity with a sensitivity of $10^{-5}$, 18-month PFS plateaued at approximately $90 \%$, an extremely good result. At the same meeting, Zimmerman et al. also reported the results of a phase 2 trial of carfilzomib-lenalidomide-dexamethasone (KRD) plus ASCT for newly diagnosed MM patients [51]. After 18 courses of KRD therapy, $86 \%$ of patients achieved CR or better, and $74 \%$ were MRD-negative with a sensitivity of $10^{-6}$. Extremely good results were achieved, with three-year PFS (86\%) and three-year OS (95\%) for all 76 patients. For MRD-negative patients by NGS, three-year PFS and three-year OS were $89 \%$ and $96 \%$, respectively, and those for MRD-positive patients by NGS were not presented. At our hospital, an analysis of MRD in BM after ASCT by NGS with a sensitivity of $10^{-6}$ found that disease progression or death will not occur in most patients even over the long term (Figure 3B,C; the reproduction of these figures is authorized) [47].

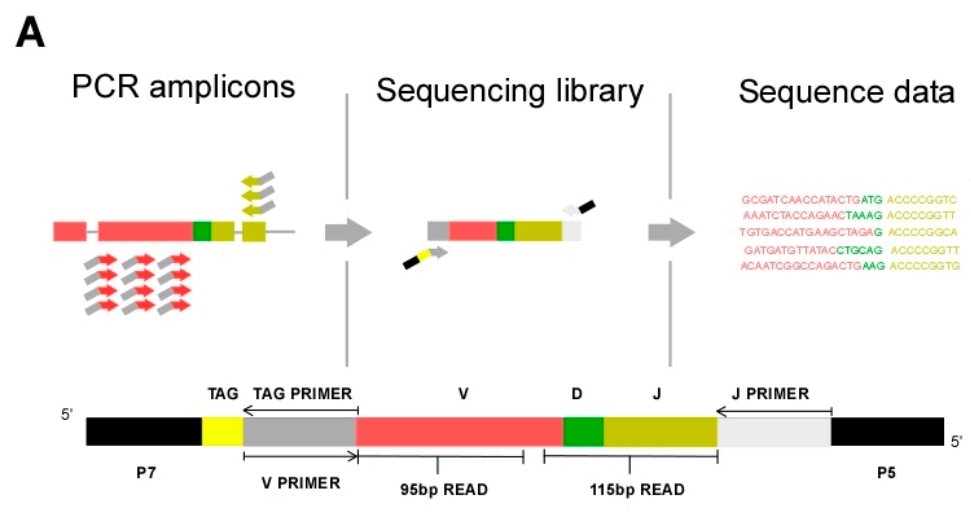

B

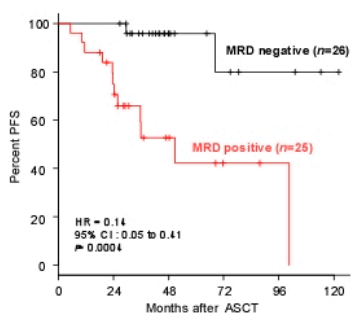

C

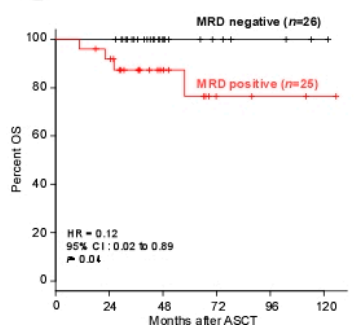

D

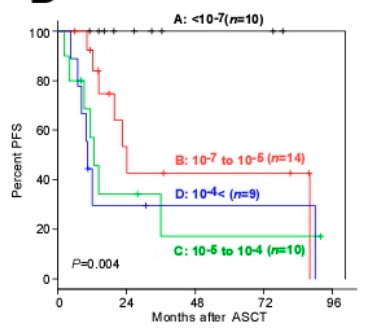

E



Figure 3. Next-generation sequencing method to detect minimal residual disease (MRD). (A) Schematic illustrations of LymphoSIGHT ${ }^{\mathrm{TM}}$ PCR primer strategy and sequencing assay. IgH V-J, IgH D-J, and IgK sequences were amplified from genomic DNA in a two-stage PCR (the first PCR using universal primer sets, and the second PCR using J primer and TAG primer). The amplified product was sequenced to obtain a high number of reads (e.g., $10^{6}$ reads). The sequence reads were analyzed to determine similar sequences that form a clonotype. After clonotype determination, a standard quantitation scheme was used to calculate MRD level [43]. (B) Progression-free survival (PFS) and (C) overall survival (OS) of patients according to the MRD negativity in post-ASCT BM samples as determined by deep sequencing (threshold: $10^{-6}$ ). (D) PFS and (E) OS of the patients who did not receive post-ASCT treatment, according to MRD negativity in the autograft as determined by deep sequencing (threshold: $10^{-7}$ ).

\subsection{MRD Assessment of Autografts}

The presence of MRD positivity in autografts indicates the presence of contaminating myeloma cells in the product, which will be infused back into the patient; however, the presence of MRD 
in the autograft could also simply show that a substantial number of myeloma cells remain in the patient's body, and that the homogenous nature of the mobilized autograft relative to the focal nature of myeloma in BM might provide a better sample to assess MRD. The contamination hypothesis might contradict previous results [52]. Stewart et al. conducted a phase III randomized trial to study whether the enrichment of $\mathrm{CD}^{+} 4^{+}$autograft cells and purging of malignant plasma cells would affect PFS and OS in a cohort of MM patients receiving autografts. Despite the significant reduction in myeloma cell contamination in the autograft (median $3.1 \log$ ), no improvement was observed in either PFS or OS. However, the application of much more effective treatments these days might change the meaning of MRD negativity in autografts.

Recently, MRD was detected in autografts used for ASCT using seven-color MFC [53]. All patients in this study underwent remission induction regimens with novel agents (carfilzomiblenalidomide-dexamethasone (KRD), $n=2$; bortezomib-cyclophosphamide-dexamethasone (VCD), $n=8$; and bortezomib-thalidomide-dexamethasone (VTD), $n=33$ ), and a good response was achieved (3 CR (7\%) and 27 VGPR (63\%) after remission induction therapy). The contamination rate in autografts with myeloma cells was extremely low in 10 of 43 patients $(23 \%)$, and those patients who underwent ASCT with MRD-negative autografts exhibited significantly better PFS than those who received MRD-positive autografts for ASCT $(p=0.008)$.

The DNA in autografts of the 22 patients who achieved at least a PR after ASCT without any post-ASCT treatments was subjected to ASO-PCR. The median PFS of the eight patients with MRD-positive autografts was 18 months, whereas that of 14 patients with MRD-negative autografts was not reached at a median follow-up of 27 months ( $p=0.012)$ [32]. We also performed ddPCR and NGS to assess MRD in the autografts of 18 of our patients who did not receive consolidation/maintenance therapy after ASCT and whose autografts were negative for MRD by ASO-qPCR [40]. Although a good correlation was found between the MRD levels of autografts measured by ddPCR and NGS, six patients (33\%) were MRD-negative by ddPCR but MRD-positive

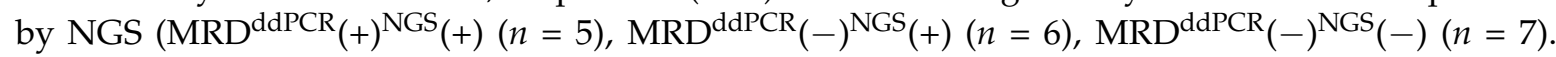
An analysis of PFS by ddPCR and NGS found that, although in both groups PFS was better for patients who underwent ASCT with MRD-negative autografts, NGS analysis allowed a more accurate prognosis (seven MRD $\left.\operatorname{MdPCR}_{(-}\right)^{\mathrm{NGS}}(-)$ cases showed significantly better PFS than six $\operatorname{MRD}^{\mathrm{ddPCR}}(-)^{\mathrm{NGS}}(+)$ (median PFS 8.4 vs. 2.0 years; $p=0.035$ ) [40]).

In our own hospital, an analysis of MRD in autografts in the ASCT setting by NGS with a sensitivity of $10^{-7}$ showed no disease progression or death in most of the MRD-negative patients, even if no further treatment was performed after ASCT, with prognosis clearly stratified by the quantitative level of MRD (Figure 3D,E; the reproduction of these figures is authorized) [47].

\section{Effect of MRD on Prognosis: Review of Previous Meta-Analyses}

There have been two recent meta-analyses of MRD in MM [54,55]. The first was a meta-analysis by Landgren et al. of four clinical trials for newly diagnosed MM patients [54], which found that MRD-negative patients showed better PFS ( $\mathrm{HR}=0.35,95 \%$ confidence interval $(\mathrm{CI}) 0.27-0.46 ; p<0.001$ ) and $\mathrm{OS}(\mathrm{HR}=0.48,95 \%$ CI 0.33-0.70; $p<0.001)$ than MRD-positive patients. The second was a meta-analysis by Munshi et al. of clinical studies of at least 20 newly diagnosed MM patients (controlled trials, randomized controlled trials, and cohort studies) [55]. This meta-analysis ultimately included 21 studies, and found that MRD-negative patients showed better PFS (HR $=0.41,95 \%$ CI $0.36-0.48 ; p<0.001)$ than MRD-positive patients, with similar results when the analysis was limited to $\mathrm{CR}$ patients $(\mathrm{HR}=0.44,95 \% \mathrm{CI} 0.34-0.56 ; p<0.001)$. MRD-negative patients also exhibited better OS (HR $=0.57,95$ CI $0.46-0.71 ; p<0.001)$, with similar results when the analysis was limited to CR patients $(\mathrm{HR}=0.47,95 \% \mathrm{CI} 0.33-0.67 ; p<0.001)$. Most subjects in these two meta-analyses underwent ASCT. These results show that even in meta-analyses covering different treatments and MRD detection methods, MRD negativity is the most powerful predictor of prognosis. 


\section{Comparison of MRD Detection Methods}

MFC can be applied in more than $90 \%$ of cases, and it is superior to ASO-qPCR in terms of both cost and speed. The EuroFlow protocol (NGF) achieves MRD detection with reproducibly high sensitivity $\left(10^{-5}-10^{-6}\right)$ and is therefore thought to be a promising method for detecting MRD. Although ASO-qPCR is more sensitive than MFC in general, the sequencing of the CDRIII region and primer design require skill, time, and a relatively higher cost, and the success rate for primer design is only around $30-80 \%$. Consequently, this method can be used in fewer patients [31]. ddPCR has problems with primer design similar to those of ASO-qPCR but does not require the generation of calibration curves and, if sufficient DNA is available, its sensitivity can theoretically exceed $10^{-6}$. Moreover, it is cheaper than NGS. ASO-qPCR and ddPCR cannot detect MRD when mutations in the CDRIII region occur [56]. On the other hand, NGS, which has recently been developed, overcomes all the above-mentioned problems with ASO-qPCR, is the most sensitive technique available, and is expected to become the main method of MRD detection. However, very few institutions are capable of carrying out NGS measurements (Table 1) [25]. In addition, because myeloma lesions are unevenly distributed in BM, a single BM aspiration test may result in a false negative result [57]. It is thus necessary to be aware of the limitations of MRD detection in BM samples, and of the need to carry out the procedure in combination with diagnostic imaging such as positron emission tomography, computed tomography, and magnetic resonance imaging.

Table 1. Comparison of MRD assays in multiple myeloma.

\begin{tabular}{|c|c|c|c|c|}
\hline & $\begin{array}{l}\text { Next-Generation } \\
\text { MFC ( } \geq 8 \text {-color) }\end{array}$ & ASO-qPCR & ASO-ddPCR & NGS \\
\hline Applicability (\%) & $\sim 100 \%$ & $\sim 80 \%$ & $\sim 80 \%$ & $90 \% \sim$ \\
\hline Sensitivity & $10^{-5} \sim 10^{-6}$ & $10^{-4} \sim 10^{-6}$ & $10^{-6} \sim$ & $10^{-6} \sim$ \\
\hline Reproducibility & High & High & Not reported & Not reported \\
\hline Diagnostic sample & $\begin{array}{l}\text { Important but } \\
\text { not mandatory }\end{array}$ & Mandatory & Mandatory & Mandatory \\
\hline MRD sample & Cells & Cells, DNA & Cells, DNA & Cells, DNA \\
\hline $\begin{array}{l}\text { Need for patient's } \\
\text { specific reagent }\end{array}$ & No & Yes & Yes & No \\
\hline $\begin{array}{l}\text { MRD detection at } \\
\text { clonal evolution }\end{array}$ & Possible & Impossible & Impossible & Possible \\
\hline Time & $3-4 \mathrm{~h}$ & $\begin{array}{c}\text { 2-3 h (follow-up), } \\
\text { 3-4 week (target } \\
\text { identification) }\end{array}$ & $\begin{array}{l}\text { 2-3 h (follow-up), } \\
\text { 3-4 week (target } \\
\text { identification) }\end{array}$ & $\geq 7 \mathrm{~d}$ \\
\hline Standardization & $\begin{array}{c}\text { Ongoing } \\
\text { (EuroFlow/IMF) }\end{array}$ & Yes (EuroMRD) & No & No \\
\hline Cost per sample & $\sim 350$ USD & $\begin{array}{l}\text { \%00 USD (follow-up), } \\
\sim 1500 \text { USD at diagnosis } \\
\text { (target identification) }\end{array}$ & $\begin{array}{l}\text { \% 500 USD (follow-up), } \\
\sim 1500 \text { USD at diagnosis } \\
\text { (target identification) }\end{array}$ & 1000 USD \\
\hline
\end{tabular}

MFC, multiparameter flow cytometry; ASO-qPCR, allele-specific oligonucleotide-quantitative polymerase chain reaction; NGS, Next-generation sequencing; MRD, minimal residual disease; IMF, International Myeloma Foundation; USD, US dollars.

\section{The Way Forward}

The stratification by MRD testing of myeloma patients who have achieved CR is essential for accurate prognosis in the future. Given that patients who are MRD-negative by a very sensitive detection method are unlikely to relapse or undergo tumor progression even if maintenance therapy is discontinued $[44,45,47,49]$, such therapy should be ceased in MRD-negative patients as part of clinical studies. 
Acknowledgments: The author would like to acknowledge Yoshiyasu Ogawa and Noriko Kobayashi of LSI Medience Corporation for their help with the preparation of the manuscript.

Author Contributions: The author wrote the paper.

Conflicts of Interest: The author received research funding from Takeda and Fujimoto, and honoraria from Celgene and Janssen.

\section{References}

1. Attal, M.; Lauwers-Cances, V.; Marit, G.; Caillot, D.; Moreau, P.; Facon, T.; Stoppa, A.M.; Hulin, C.; Benboubker, L.; Garderet, L.; et al. Lenalidomide maintenance after stem-cell transplantation for multiple myeloma. N. Engl. J. Med. 2012, 366, 1782-1791. [CrossRef] [PubMed]

2. McCarthy, P.L.; Owzar, K.; Hofmeister, C.C.; Hurd, D.D.; Hassoun, H.; Richardson, P.G.; Giralt, S.; Stadtmauer, E.A.; Weisdorf, D.J.; Vij, R.; et al. Lenalidomide after stem-cell transplantation for multiple myeloma. N. Engl. J. Med. 2012, 366, 1770-1781. [CrossRef] [PubMed]

3. San Miguel, J.F.; Schlag, R.; Khuageva, N.K.; Dimopoulos, M.A.; Shpilberg, O.; Kropff, M.; Spicka, I.; Petrucci, M.T.; Palumbo, A.; Samoilova, O.S.; et al. Bortezomib plus melphalan and prednisone for initial treatment of multiple myeloma. N. Engl. J. Med. 2008, 359, 906-917. [CrossRef] [PubMed]

4. Stewart, A.K.; Rajkumar, S.V.; Dimopoulos, M.A.; Masszi, T.; Spicka, I.; Oriol, A.; Hajek, R.; Rosinol, L.; Siegel, D.S.; Mihaylov, G.G.; et al. Carfilzomib, lenalidomide, and dexamethasone for relapsed multiple myeloma. N. Engl. J. Med. 2015, 372, 142-152. [CrossRef] [PubMed]

5. Moreau, P.; Masszi, T.; Grzasko, N.; Bahlis, N.J.; Hansson, M.; Pour, L.; Sandhu, I.; Ganly, P.; Baker, B.W.; Jackson, S.R.; et al. Oral ixazomib, lenalidomide, and dexamethasone for multiple myeloma. N. Engl. J. Med. 2016, 374, 1621-1634. [CrossRef] [PubMed]

6. Benboubker, L.; Dimopoulos, M.A.; Dispenzieri, A.; Catalano, J.; Belch, A.R.; Cavo, M.; Pinto, A.; Weisel, K.; Ludwig, H.; Bahlis, N.; et al. Lenalidomide and dexamethasone in transplant-ineligible patients with myeloma. N. Engl. J. Med. 2014, 371, 906-917. [CrossRef] [PubMed]

7. Cavo, M.; Tacchetti, P.; Patriarca, F.; Petrucci, M.T.; Pantani, L.; Galli, M.; Di Raimondo, F.; Crippa, C.; Zamagni, E.; Palumbo, A.; et al. Bortezomib with thalidomide plus dexamethasone compared with thalidomide plus dexamethasone as induction therapy before, and consolidation therapy after, double autologous stem-cell transplantation in newly diagnosed multiple myeloma: A randomised phase 3 study. Lancet 2010, 376, 2075-2085. [PubMed]

8. San Miguel, J.; Weisel, K.; Moreau, P.; Lacy, M.; Song, K.; Delforge, M.; Karlin, L.; Goldschmidt, H.; Banos, A.; Oriol, A.; et al. Pomalidomide plus low-dose dexamethasone versus high-dose dexamethasone alone for patients with relapsed and refractory multiple myeloma (MM-003): A randomised, open-label, phase 3 trial. Lancet Oncol. 2013, 14, 1055-1066. [CrossRef]

9. Lonial, S.; Dimopoulos, M.; Palumbo, A.; White, D.; Grosicki, S.; Spicka, I.; Walter-Croneck, A.; Moreau, P.; Mateos, M.V.; Magen, H.; et al. Elotuzumab therapy for relapsed or refractory multiple myeloma. N. Engl. J. Med. 2015, 373, 621-631. [CrossRef] [PubMed]

10. Dimopoulos, M.A.; Oriol, A.; Nahi, H.; San-Miguel, J.; Bahlis, N.J.; Usmani, S.Z.; Rabin, N.; Orlowski, R.Z.; Komarnicki, M.; Suzuki, K.; et al. Daratumumab, lenalidomide, and dexamethasone for multiple myeloma. N. Engl. J. Med. 2016, 375, 1319-1331. [CrossRef] [PubMed]

11. Palumbo, A.; Chanan-Khan, A.; Weisel, K.; Nooka, A.K.; Masszi, T.; Beksac, M.; Spicka, I.; Hungria, V.; Munder, M.; Mateos, M.V.; et al. Daratumumab, bortezomib, and dexamethasone for multiple myeloma. N. Engl. J. Med. 2016, 375, 754-766. [CrossRef] [PubMed]

12. Mailankody, S.; Korde, N.; Lesokhin, A.M.; Lendvai, N.; Hassoun, H.; Stetler-Stevenson, M.; Landgren, O. Minimal residual disease in multiple myeloma: Bringing the bench to the bedside. Nat. Rev. Clin. Oncol. 2015, 12, 286-295. [CrossRef] [PubMed]

13. Kumar, S.; Paiva, B.; Anderson, K.C.; Durie, B.; Landgren, O.; Moreau, P.; Munshi, N.; Lonial, S.; Blade, J.; Mateos, M.V.; et al. International Myeloma Working Group consensus criteria for response and minimal residual disease assessment in multiple myeloma. Lancet Oncol. 2016, 17, e328-e346. [CrossRef]

14. Rawstron, A.C.; Child, J.A.; de Tute, R.M.; Davies, F.E.; Gregory, W.M.; Bell, S.E.; Szubert, A.J.; Navarro-Coy, N.; Drayson, M.T.; Feyler, S.; et al. Minimal residual disease assessed by multiparameter flow cytometry in multiple myeloma: Impact on outcome in the Medical Research Council Myeloma IX Study. J. Clin. Oncol. 2013, 31, 2540-2547. [CrossRef] [PubMed] 
15. Puig, N.; Sarasquete, M.E.; Balanzategui, A.; Martinez, J.; Paiva, B.; Garcia, H.; Fumero, S.; Jimenez, C.; Alcoceba, M.; Chillon, M.C.; et al. Critical evaluation of ASO RQ-PCR for minimal residual disease evaluation in multiple myeloma. A comparative analysis with flow cytometry. Leukemia 2014, 28, 391-397. [CrossRef] [PubMed]

16. Paiva, B.; Vidriales, M.B.; Cervero, J.; Mateo, G.; Perez, J.J.; Montalban, M.A.; Sureda, A.; Montejano, L.; Gutierrez, N.C.; Garcia de Coca, A.; et al. Multiparameter flow cytometric remission is the most relevant prognostic factor for multiple myeloma patients who undergo autologous stem cell transplantation. Blood 2008, 112, 4017-4023. [CrossRef] [PubMed]

17. Mateos, M.V.; Oriol, A.; Martinez-Lopez, J.; Teruel, A.I.; Lopez de la Guia, A.; Lopez, J.; Bengoechea, E.; Perez, M.; Martinez, R.; Palomera, L.; et al. GEM2005 trial update comparing VMP/VTP as induction in elderly multiple myeloma patients: Do we still need alkylators? Blood 2014, 124, 1887-1893. [CrossRef] [PubMed]

18. Dal Bo, S.; Pezzi, A.; Amorin, B.; Valim, V.; Isabel Bittencourt, R.; Silla, L. Detection of minimal residual disease by flow cytometry for patients with multiple myeloma submitted to autologous hematopoietic stem cell transplantation. ISRN Hematol. 2013, 2013, 847672. [CrossRef] [PubMed]

19. Paiva, B.; Martinez-Lopez, J.; Vidriales, M.B.; Mateos, M.V.; Montalban, M.A.; Fernandez-Redondo, E.; Alonso, L.; Oriol, A.; Teruel, A.I.; de Paz, R.; et al. Comparison of immunofixation, serum free light chain, and immunophenotyping for response evaluation and prognostication in multiple myeloma. J. Clin. Oncol. 2011, 29, 1627-1633. [CrossRef] [PubMed]

20. Roussel, M.; Lauwers-Cances, V.; Robillard, N.; Hulin, C.; Leleu, X.; Benboubker, L.; Marit, G.; Moreau, P.; Pegourie, B.; Caillot, D.; et al. Front-line transplantation program With lenalidomide, bortezomib, and dexamethasone combination as induction and consolidation followed by lenalidomide maintenance in patients with multiple myeloma: A phase II study by the Intergroupe Francophone du Myelome. J. Clin. Oncol. 2014, 32, 2712-2717. [PubMed]

21. Fukumoto, K.; Fujisawa, M.; Suehara, Y.; Narita, K.T.; Usui, Y.; Takeuchi, M.; Matsue, K. Prognostic impact of immunophenotypic complete response in patients with multiple myeloma achieving better than complete response. Leuk. Lymphoma 2016, 57, 1786-1792. [CrossRef] [PubMed]

22. Ludwig, H.; Greil, R.; Masszi, T.; Spicka, I.; Shpilberg, O.; Hajek, R.; Dmoszynska, A.; Paiva, B.; Vidriales, M.B.; Esteves, G.; et al. Bortezomib, thalidomide and dexamethasone, with or without cyclophosphamide, for patients with previously untreated multiple myeloma: 5-year follow-up. Br. J. Haematol. 2015, 171, 344-354. [CrossRef] [PubMed]

23. Rajkumar, S.V.; Harousseau, J.L.; Durie, B.; Anderson, K.C.; Dimopoulos, M.; Kyle, R.; Blade, J.; Richardson, P.; Orlowski, R.; Siegel, D.; et al. Consensus recommendations for the uniform reporting of clinical trials: Report of the International Myeloma Workshop Consensus Panel 1. Blood 2011, 117, 4691-4695. [CrossRef] [PubMed]

24. Rawstron, A.C.; Gregory, W.M.; de Tute, R.M.; Davies, F.E.; Bell, S.E.; Drayson, M.T.; Cook, G.; Jackson, G.H.; Morgan, G.J.; Child, J.A.; et al. Minimal residual disease in myeloma by flow cytometry: Independent prediction of survival benefit per log reduction. Blood 2015, 125, 1932-1935. [CrossRef] [PubMed]

25. Paiva, B.; van Dongen, J.J.; Orfao, A. New criteria for response assessment: Role of minimal residual disease in multiple myeloma. Blood 2015, 125, 3059-3068. [CrossRef] [PubMed]

26. Paiva, B.; Cedena, M.T.; Puig, N.; Arana, P.; Vidriales, M.B.; Cordon, L.; Flores-Montero, J.; Gutierrez, N.C.; Martin-Ramos, M.L.; Martinez-Lopez, J.; et al. Minimal residual disease monitoring and immune profiling in multiple myeloma in elderly patients. Blood 2016, 127, 3165-3174. [CrossRef] [PubMed]

27. Flanders, A.; Stetler-Stevenson, M.; Landgren, O. Minimal residual disease testing in multiple myeloma by flow cytometry: Major heterogeneity. Blood 2013, 122, 1088-1089. [CrossRef] [PubMed]

28. Cao, W.; Goolsby, C.L.; Nelson, B.P.; Singhal, S.; Mehta, J.; Peterson, L.C. Instability of immunophenotype in plasma cell myeloma. Am. J. Clin. Pathol. 2008, 129, 926-933. [CrossRef] [PubMed]

29. Flores-Montero, J.; Sanoja-Flores, L.; Paiva, B.; Puig, N.; Garcia-Sanchez, O.; Bottcher, S.; van der Velden, V.H.; Perez-Moran, J.J.; Vidriales, M.B.; Garcia-Sanz, R.; et al. Next Generation Flow for highly sensitive and standardized detection of minimal residual disease in multiple myeloma. Leukemia 2017. [CrossRef] [PubMed]

30. van der Velden, V.H.; van Dongen, J.J. MRD detection in acute lymphoblastic leukemia patients using Ig/TCR gene rearrangements as targets for real-time quantitative PCR. Methods Mol. Biol. 2009, 538, 115-150. [PubMed] 
31. Ladetto, M.; Pagliano, G.; Ferrero, S.; Cavallo, F.; Drandi, D.; Santo, L.; Crippa, C.; De Rosa, L.; Pregno, P.; Grasso, M.; et al. Major tumor shrinking and persistent molecular remissions after consolidation with bortezomib, thalidomide, and dexamethasone in patients with autografted myeloma. J. Clin. Oncol. 2010, 28, 2077-2084. [CrossRef] [PubMed]

32. Takamatsu, H.; Ogawa, Y.; Kobayashi, N.; Obata, K.; Narisawa, T.; Nakayama, K.; Munemoto, S.; Aoki, G.; Ohata, K.; Kumano, Y.; et al. Detection of minimal residual disease in patients with multiple myeloma using clonotype-specific PCR primers designed from DNA extracted from archival bone marrow slides. Exp. Hematol. 2013, 41, 894-902. [CrossRef] [PubMed]

33. Ferrero, S.; Ladetto, M.; Drandi, D.; Cavallo, F.; Genuardi, E.; Urbano, M.; Caltagirone, S.; Grasso, M.; Rossini, F.; Guglielmelli, T.; et al. Long-term results of the GIMEMA VEL-03-096 trial in MM patients receiving VTD consolidation after ASCT: MRD kinetics' impact on survival. Leukemia 2015, 29, 689-695. [CrossRef] [PubMed]

34. Silvennoinen, R.; Kairisto, V.; Pelliniemi, T.T.; Putkonen, M.; Anttila, P.; Saily, M.; Sikio, A.; Opas, J.; Penttila, K.; Kuittinen, T.; et al. Assessment of molecular remission rate after bortezomib plus dexamethasone induction treatment and autologous stem cell transplantation in newly diagnosed multiple myeloma patients. Br. J. Haematol. 2013, 160, 561-564. [CrossRef] [PubMed]

35. Korthals, M.; Sehnke, N.; Kronenwett, R.; Bruns, I.; Mau, J.; Zohren, F.; Haas, R.; Kobbe, G.; Fenk, R. The level of minimal residual disease in the bone marrow of patients with multiple myeloma before high-dose therapy and autologous blood stem cell transplantation is an independent predictive parameter. Biol. Blood Marrow Transplant. 2012, 18, 423-431. [CrossRef] [PubMed]

36. Korthals, M.; Sehnke, N.; Kronenwett, R.; Schroeder, T.; Strapatsas, T.; Kobbe, G.; Haas, R.; Fenk, R. Molecular monitoring of minimal residual disease in the peripheral blood of patients with multiple myeloma. Biol. Blood Marrow Transplant. 2013, 19, 1109-1115. [CrossRef] [PubMed]

37. Oliva, S.; Gambella, M.; Gilestro, M.; Muccio, V.E.; Gay, F.; Drandi, D.; Ferrero, S.; Passera, R.; Pautasso, C.; Bernardini, A.; et al. Minimal residual disease after transplantation or lenalidomide-based consolidation in myeloma patients: A prospective analysis. Oncotarget 2017, 8, 5924-5935. [CrossRef] [PubMed]

38. Oliva, S.; Gambella, M.; Larocca, A.; Spada, S.; Marzanati, E.; Mantoan, B.; Grammatico, S.; Conticello, C.; Gamberi, B.; Offidani, M.; et al. Prognostic impact of minimal residual disease by ASO-RQ-PCR in multiple myeloma: A pooled analysis of 2 phase III studies in patients treated with lenalidomide after front-line therapy. Blood 2016, 128, 4409.

39. van der Velden, V.H.; Cazzaniga, G.; Schrauder, A.; Hancock, J.; Bader, P.; Panzer-Grumayer, E.R.; Flohr, T.; Sutton, R.; Cave, H.; Madsen, H.O.; et al. Analysis of minimal residual disease by Ig/TCR gene rearrangements: Guidelines for interpretation of real-time quantitative PCR data. Leukemia 2007, 21, 604-611. [CrossRef] [PubMed]

40. Takamatsu, H.; Wee, R.; Zaimoku, Y.; Murata, R.; Zheng, J.; Moorhead, M.; Carlton, V.E.H.; Takezako, N.; Ito, S.; Miyamoto, T.; et al. A comparison of minimal residual disease detection in autografts among ASO-qPCR, droplet digital PCR, and next-generation sequencing in patients with multiple myeloma who underwent autologous stem cell transplantation. Br. J. Haematol. 2017, in press.

41. Drandi, D.; Kubiczkova-Besse, L.; Ferrero, S.; Dani, N.; Passera, R.; Mantoan, B.; Gambella, M.; Monitillo, L.; Saraci, E.; Ghione, P.; et al. Minimal Residual Disease Detection by Droplet Digital PCR in Multiple Myeloma, Mantle Cell Lymphoma, and Follicular Lymphoma: A Comparison with Real-Time PCR. J. Mol. Diagn. 2015, 17, 652-660. [CrossRef] [PubMed]

42. Martinez-Lopez, J.; Lahuerta, J.J.; Pepin, F.; Gonzalez, M.; Barrio, S.; Ayala, R.; Puig, N.; Montalban, M.A.; Paiva, B.; Weng, L.; et al. Prognostic value of deep sequencing method for minimal residual disease detection in multiple myeloma. Blood 2014, 123, 3073-3079. [CrossRef] [PubMed]

43. Faham, M.; Zheng, J.; Moorhead, M.; Carlton, V.E.; Stow, P.; Coustan-Smith, E.; Pui, C.H.; Campana, D. Deep-sequencing approach for minimal residual disease detection in acute lymphoblastic leukemia. Blood 2012, 120, 5173-5180. [CrossRef] [PubMed]

44. Schinke, C.; Deshpande, S.; Mitchell, A.; Faham, M.; Patel, P.; Thanendrarajan, S.; Mohan, M.; Mathur, P.; Matin, A.; Radhakrishnan, M.; et al. Impact of minimal residual disease in high and standard risk multiple myeloma. Blood 2015, 126, 2979. 
45. Korde, N.; Roschewski, M.; Zingone, A.; Kwok, M.; Manasanch, E.E.; Bhutani, M.; Tageja, N.; Kazandjian, D.; Mailankody, S.; Wu, P.; et al. Treatment with carfilzomib-lenalidomide-dexamethasone with lenalidomide extension in patients with smoldering or newly diagnosed multiple myeloma. JAMA Oncol. 2015, 1, 746-754. [CrossRef] [PubMed]

46. Martinez-Lopez, J.; Sanchez-Vega, B.; Barrio, S.; Cuenca, I.; Ruiz-Heredia, Y.; Alonso, R.; Rapado, I.; Marin, C.; Cedena, M.T.; Paiva, B.; et al. Analytical and clinical validation of a novel in-house deep-sequencing method for minimal residual disease monitoring in a phase II trial for multiple myeloma. Leukemia 2017, 31, 1446-1449. [CrossRef] [PubMed]

47. Takamatsu, H.; Takezako, N.; Zheng, J.; Moorhead, M.; Carlton, V.; Kong, K.; Murata, R.; Ito, S.; Miyamoto, T.; Yokoyama, K.; et al. Prognostic value of sequencing-based minimal residual disease detection in patients with multiple myeloma who underwent autologous stem cell transplantation. Ann. Oncol. 2017, in press. [CrossRef]

48. Attal, M.; Lauwers-Cances, V.; Hulin, C.; Leleu, X.; Caillot, D.; Escoffre, M.; Arnulf, B.; Macro, M.; Belhadj, K.; Garderet, L.; et al. Lenalidomide, bortezomib, and dexamethasone with transplantation for myeloma. N. Engl. J. Med. 2017, 376, 1311-1320. [CrossRef] [PubMed]

49. Avet-Loiseau, H.; Corre, J.; Lauwers-Cances, V.; Chretien, M.; Robillard, N.; Leleu, X.; Hulin, C.; Gentil, C.; Arnulf, B.; Belhadj, K.; et al. Evaluation of minimal residual disease (MRD) by next generation sequencing (NGS) is highly predictive of progression free survival in the IFM/DFCI 2009 trial. Blood 2015, 126, 191.

50. Avet-Loiseau, H.; Casneuf, T.; Chiu, C.; Laubach, J.; Lee, J.; Moreau, P.; Plesner, T.; Nahi, H.; Khokhar, N.; Qi, M.; et al. Evaluation of minimal residual disease (MRD) in relapsed/refractory multiple myeloma (RRMM) patients treated with daratumumab in combination with lenalidomide plus dexamethasone or bortezomib plus dexamethasone. Blood 2016, 128, 246.

51. Zimmerman, T.M.; Raje, N.; Vij, R.; Reece, D.; Berdeja, J.G.; Stephens, L.; McDonnell, K.; Rosenbaum, C.A.; Jasielec, J.K.; Richardson, P.; et al. Final results of a phase 2 trial of extended treatment with carfilzomib, lenalidomide, and dexamethasone (KRd) plus autologous stem cell transplant (ASCT) in newly diagnosed multiple myeloma. Blood 2016, 128, 675 .

52. Stewart, A.K.; Vescio, R.; Schiller, G.; Ballester, O.; Noga, S.; Rugo, H.; Freytes, C.; Stadtmauer, E.; Tarantolo, S.; Sahebi, F; et al. Purging of autologous peripheral-blood stem cells using CD34 selection does not improve overall or progression-free survival after high-dose chemotherapy for multiple myeloma: Results of a multicenter randomized controlled trial. J. Clin. Oncol. 2001, 19, 3771-3779. [CrossRef] [PubMed]

53. Wuilleme, S.; Lok, A.; Robillard, N.; Dupuis, P.; Stocco, V.; Migne, H.; Dusquesne, A.; Touzeau, C.; Tiab, M.; Bene, M.C.; et al. Assessment of tumoral plasma cells in apheresis products for autologous stem cell transplantation in multiple myeloma. Bone Marrow Transplant. 2016, 51, 1143-1145. [CrossRef] [PubMed]

54. Landgren, O.; Devlin, S.; Boulad, M.; Mailankody, S. Role of MRD status in relation to clinical outcomes in newly diagnosed multiple myeloma patients: A meta-analysis. Bone Marrow Transplant. 2016, 51, 1565-1568. [CrossRef] [PubMed]

55. Munshi, N.C.; Avet-Loiseau, H.; Rawstron, A.C.; Owen, R.G.; Child, J.A.; Thakurta, A.; Sherrington, P.; Samur, M.K.; Georgieva, A.; Anderson, K.C.; et al. Association of minimal residual disease with superior survival outcomes in patients with multiple myeloma: A meta-analysis. JAMA Oncol. 2017, 3, 28-35. [CrossRef] [PubMed]

56. Munshi, N.C.; Martinez-Lopez, J.; Carlton, V.; Minvielle, S.; Tai, Y.; Fulciniti, M.; Samur, M.K.; Richardson, P.G.; Attal, M.; Moreau, P.; et al. A Novel Evolutionary Pattern Revealed Using Deep Sequencing of Immunoglobulin Loci at Diagnosis and over the Course of Treatment in Multiple Myeloma Patients. Blood 2016, 128, 238.

57. Davies, F.E.; Rawstron, A.C.; Owen, R.G.; Morgan, G.J. Minimal residual disease monitoring in multiple myeloma. Best Pract. Res. Clin. Haematol. 2002, 15, 197-222. [CrossRef] [PubMed]

(C) 2017 by the author. Licensee MDPI, Basel, Switzerland. This article is an open access article distributed under the terms and conditions of the Creative Commons Attribution (CC BY) license (http:/ / creativecommons.org/licenses/by/4.0/). 